\title{
Benchmarking experience to improve paediatric healthcare: listening to the voices of families from two European Children's University Hospitals
}

\author{
Ilaria Corazza ${ }^{1 *}$ (D), Kendall Jamieson Gilmore ${ }^{1}$, Francesca Menegazzo ${ }^{2}$ and Valts Abols ${ }^{3}$
}

\begin{abstract}
Background: Patient Reported Experience Measures (PREMs) are recognized as an important indicator of high quality care and person-centeredness. PREMs are increasingly adopted for paediatric care, but there is little published evidence on how to administer, collect, and report paediatric PREMs at scale.

Methods: This paper describes the development of a PREMs questionnaire and administration system for the Meyer Children's University Hospital in Florence (Meyer) and the Children's Clinical University Hospital in Riga (CCUH). The system continuously recruits participants into the electronic administration model, with surveys completed by caregivers or adolescents at their convenience, post-discharge. We analyse 1661 responses from Meyer and 6585 from CCUH, collected from 1st December 2018 to 21st January 2020. Quantitative and qualitative experience analyses are included, using Pearson chi-square tests, Fisher's exact tests and narrative evidence from free text responses.

Results: The large populations reached in both countries suggest the continuous, digital collection of paediatric PREMs described is feasible for collecting paediatric PREMs at scale. Overall response rates were 59\% in Meyer and 45\% in CCUH. There was very low variation in mean scores between the hospitals, with greater clustering of Likert scores around the mean in CCUH and a wider spread in Meyer for a number of items. The significant majority of responses represent the carers' point of view or the perspective of children and adolescents expressed through proxy reporting by carers.

Conclusions: Very similar reported scores may reflect broadly shared preferences among children, adolescents and carers in the two countries, and the ability of both hospitals in this study to meet their expectations.

The model has several interesting features: inclusion of a narrative element; electronic administration and completion after discharge from hospital, with high completion rates and easy data management; access for staff and researchers through an online platform, with real time analysis and visualization; dual implementation in two sites in different settings, with comparison and shared learning. These bring new opportunities for the utilization of PREMs for more person-centered and better quality care, although further research is needed in order to access direct reporting by children and adolescents.
\end{abstract}

Keywords: Benchmarking, Patient reported experience measures, Paediatric care

\footnotetext{
* Correspondence: ilaria.corazza@santannapisa.it

${ }^{1}$ Management and Healthcare Laboratory (MeS Lab), Institute of

Management and EMbeDS, Sant'Anna School of Advanced Studies, Piazza

Martiri della Libertà 33, 56127 Pisa, Italy

Full list of author information is available at the end of the article
}

(c) The Author(s). 2021 Open Access This article is licensed under a Creative Commons Attribution 4.0 International License, which permits use, sharing, adaptation, distribution and reproduction in any medium or format, as long as you give appropriate credit to the original author(s) and the source, provide a link to the Creative Commons licence, and indicate if changes were made. The images or other third party material in this article are included in the article's Creative Commons licence, unless indicated otherwise in a credit line to the material. If material is not included in the article's Creative Commons licence and your intended use is not permitted by statutory regulation or exceeds the permitted use, you will need to obtain permission directly from the copyright holder. To view a copy of this licence, visit http://creativecommons.org/licenses/by/4.0/. The Creative Commons Public Domain Dedication waiver (http://creativecommons.org/publicdomain/zero/1.0/) applies to the data made available in this article, unless otherwise stated in a credit line to the data. 


\section{Background}

Patient experience is recognized as an important measure of performance in healthcare; not just as a 'nice to have' in addition to good clinical care, but an integral element of delivering quality healthcare [1]. As well as a worthy aim in itself, there is evidence that better patient experiences are associated with a number of desirable effects: positive patient behaviors, including adherence to clinical advice and treatments; better clinical outcomes; and reduced unnecessary healthcare usage [2]. These findings have been recorded elsewhere, alongside consistent positive associations between patient experience, safety, and clinical effectiveness [3].

Providing a positive patient experience is increasingly a core aim at many levels in health systems, and is one of the features in the Quadruple Aim, a model consisting of achieving sustainable cost, better population health, improved patient experience and improved provider experience [4]. Additionally, patient experience data can be used alongside other data to better measure and facilitate value-based care at population levels [5-7]. Patient experience is widely measured using Patient Reported Experience Measures (PREMs), which capture different elements of what happened in hospital (e.g. communication at discharge, ward environment) and can be used to recreate what a patient experienced during their interactions with healthcare providers as well as their overall perception of care [8].

This increased focus on PREMs is not evenly spread, with some populations or clinical areas not typically included in PREMs collection [9]. One such area is paediatric care, which, despite internationally agreed statements on the rights of children to be consulted and involved in decision making, and agreement by health services researchers of the need to include children's views, remain an underrepresented group [10,11]. There are several possible reasons for this: a residual view that children are not sufficiently developed to be able to meaningfully contribute [12]; comparatively little evidence on the best mechanisms for collecting paediatric experience data [10]; and, perceived and real challenges in enabling children to adequately describe their experiences to adults collecting such data. However, studies have shown that even young children have the capacity to understand their condition and care [13], and children's comments are coherent and pertinent to hospitalization experiences [11, 14]. Additionally, there are comparatively few paediatric hospitals (where dedicated paediatric PREMs are more likely to be feasible) compared to generalist hospitals, which may further limit the availability of paediatric PREM data.

Taken together, this dearth of paediatric patient experience data could have a number of potentially detrimental effects: a reduced understanding of what children and adolescents in hospital (and their caregivers) value; missed opportunities for providing more patient-centred care; and a lack of understanding about the relationship between experience, outcomes, and ways of working in healthcare settings.

In particular, an inability to record, benchmark and compare performance on shared paediatric experience measures removes a set of levers to improve provider performance. Benchmarking and disclosure is known to be an effective means to improve health care [15], and the opportunities to do so for patient reported measures were highlighted recently by the Organisation for Economic Co-operation and Development (OECD), which emphasized the need to conduct international benchmarking of PREMs [9]. To benchmark effectively requires sufficient data, which is comparable, relevant, timely and actionable. For paediatric care, this is a particular challenge for the reasons stated above, leading to lost opportunities to learn from different providers and systems, and to improve the quality of care for children and adolescents in hospital.

This paper describes a model for and results from collecting and comparing paediatric PREMs in Italy and Latvia. In doing so, it explores the feasibility of establishing an international PREMs benchmarking observatory, making use of digital and continuous collection using a shared system and support function. The results from the two areas are compared and evaluated, to provide a picture of the ways in which children and adolescents in hospital and their caregivers do or do not provide the same responses at international level.

The aims of this work are to:

1) explore the feasibility of establishing an international benchmarking system for PREMs, starting with specialist paediatric hospitals in two countries, Italy and Latvia; and

2) compare responses between the two hospitals and conduct international benchmarking of paediatric PREMs.

\section{Methods}

\section{Setting}

The study was conducted in the Meyer Children's University Hospital in Florence (Meyer), Italy, and the Children's Clinical University Hospital in Riga (CCUH), Latvia. Both are specialist paediatric hospitals offering the full range of paediatric emergency and inpatient services.

In Florence, the paediatric PREMs programme was developed as an extension to the ongoing collection of adult PREMs in several hospitals in the surrounding Tuscany region and more widely. In Riga, the pilot collection of paediatric PREMs was implemented as part of 
an European Commission Structural Reform Support Service (SRSS) to develop a Health System Performance Assessment (HSPA) system in Latvia [16]. The Children's Clinical University Hospital elected to undertake the first PREMs collection and reporting in Latvia through that reform initiative. Both programmes are delivered with support from the Management and Healthcare Laboratory (MeS Lab) of the Sant'Anna School of Advanced Studies in Pisa.

\section{Institutional context}

Meyer and CCUH use different diagnosis-related group (DRG) systems, preventing direct case-mix comparison. More generally, both hospitals attract patients from large territories and treat complex cases.

Meyer is a first level referral center for the local catchment area, and also attracts regional, extraregional and international patients through its role as referral center in the Regional Paediatric Network, and through its specializations recognized nationally and internationally. Overall, 26\% of Meyer patients in the past five years have been from outside the Tuscany region.

CCUH is the only tertiary hospital for children in Latvia providing multidisciplinary care in more than 40 specialties, and educational and science programs for health professionals. CCUH serves as ultimate referral center for children from all Latvia. CCUH is an expert in developing and improving health literacy for children's health care in Latvia.

Further information about the respective institutional contexts, is provided in Table 1:

\section{Survey administration and data management}

The survey is conducted digitally. During the hospital stay, all patients and carers are informed about the PREMs programme by ward staff, and carers are invited to provide contact details upon discharge from the ward on patients' behalf. There are no exclusion criteria for participants (both patients and carers) in the survey, as one of the main purposes of this study is to test the feasibility of implementing a census-like survey of paediatric PREMs at the hospital level. More specifically, Meyer takes an opt-in enrolment approach while CCUH takes an opt-out enrolment approach. Patients who consent have a flag included in their electronic record, which are then accessed by the MeS Lab servers through an Application Programming Interface (API). This provides a continuous data flow between the PREMs administration system and participating hospitals. This data flow includes: admitting and discharging wards; date of admission and discharge; citizenship, sex and age of the paediatric patient. The process is conducted automatically and anonymously. Contact data are deleted or encrypted after recall or questionnaire completion, whichever is the first.

Within $24 \mathrm{~h}$ of discharge, enrolled carers are automatically sent a text message or email containing a unique link through which to access the survey. A reminder is sent $24 \mathrm{~h}$ later if the survey has not been accessed.

Survey responses are securely collated, analysed and visualised in real time through a web platform. Each hospital is able to review their quantitative data in aggregate form, with qualitative comments included in a separate feed. Through the web platform, the data can be segmented and viewed in various ways, for example by

Table 1 Institutional context of Meyer and CCUH

\begin{tabular}{|c|c|c|}
\hline & Meyer & $\mathrm{CCUH}$ \\
\hline $\begin{array}{l}\text { Ownership } \\
\text { and structure }\end{array}$ & $\begin{array}{l}\text { - Publicly-held } \\
\text { - } 250 \text { multi-specialist beds } \\
\text { - Around } 1400 \text { staff }\end{array}$ & $\begin{array}{l}\text { - Publicly-held } \\
\text { - } 300 \text { multi-specialist beds } \\
\text { - Around } 1920 \text { staff }\end{array}$ \\
\hline Services & $\begin{array}{l}\text { - Emergency medical services and observation } \\
\text { - Stationary medical care } \\
\text { - Ambulatory medical care } \\
\text { - Daytime stationary } \\
\text { - Diagnostic services and prophylaxis } \\
\text { - Rehabilitation services } \\
\text { - Rare diseases reference and coordination centre of the Tuscany Region }\end{array}$ & $\begin{array}{l}\text { - Emergency medical services and observation } \\
\text { - Stationary medical care } \\
\text { - Ambulatory medical care } \\
\text { - Daytime stationary } \\
\text { - Diagnostic services and prophylaxis } \\
\text { - Rehabilitation services } \\
\text { - Rare disease coordination centre } \\
\text { - Sports medical centre } \\
\text { - Epilepsy and sleep medicine centre } \\
\text { - Children's vaccination centre }\end{array}$ \\
\hline Research & - Collaborating with the University of Florence & $\begin{array}{l}\text { - Collaborating with the Riga Stradins University and } \\
\text { the Medical Faculty of Latvian State University }\end{array}$ \\
\hline Networks & $\begin{array}{l}\text { - (Regional) Paediatric Network of Tuscany Region } \\
\text { - (National) Italian Association of Paediatric Hospitals } \\
\text { - (International) European Children's Hospital Organisation, European } \\
\text { Reference Networks for rare diseases, a number of partnerships with other } \\
\text { healthcare and academic institutions, e. g. Children's Hospital Association, } \\
\text { Children's Hospital of Philadelphia and Boston Children's Hospital }\end{array}$ & $\begin{array}{l}\text { - (International) European Children's Hospital } \\
\text { Organisation, Planetree International, European } \\
\text { Reference Networks for rare diseases }\end{array}$ \\
\hline
\end{tabular}


time period or by discharging ward. Professionals can thereby consult the data related to their own patients, not only at hospital level.

\section{Questionnaire characteristics}

To develop a PREMs survey for use in paediatric settings, the standard Tuscan adult survey - based on a longstanding PREMs survey used in the region, initially based on items from the Picker Institute [6] - was adapted by researchers at the MeS Lab, including through addition of items from the Consumer Assessment of Healthcare Providers and Systems (CAHPS) Child Hospital Survey which has been previously validated, including in international settings [17]. The surveys were then revised and further developed with hospital teams to reflect the local context. Most items are very similar to - or are translated items from - previously validated surveys. The resultant surveys are of differing lengths (63 questions in Riga, 55 in Florence), contain a majority of identical items, and contain the same sections capturing the patient journey:
A. Hospital admission;
B. Child's/Adolescent's hospitalization experience;
C. Caregiver's experience;
D. Hospital environment;
E. Discharge;
F. Overall evaluation;
G. Post-hospitalization phase; and
H. Caregiver's characteristics.

The primary difference between the two surveys is that the questionnaire addressed to $\mathrm{CCUH}$ patients and caregivers includes questions for measuring their experience in the Emergency Department, while the questionnaire addressed to Meyer patients and caregivers does not. Comparison of scores is therefore possible for most, but not all, items.

The questionnaires seek to highlight the voice of children and adolescents, including a section for completion directly by patients, and the opportunity for those older than 13 years to complete the majority of the survey autonomously.

Both surveys contain several open-ended questions, addressed to both children and adolescents directly and to caregivers, to enable them comment in more detail and more widely than typical closed-ended experiential questions allow.

For a full view of questions and response options/ scales, please see the questionnaire reported online as additional material.

\section{Analysis of responses Quantitative analysis}

Statistical quantitative analysis was performed in Stata 15, using experience data collected from 1st December 2018 to 21st January 2020.
Confirmatory factor analysis was conducted on relevant survey sections for the two hospitals' PREM survey responses separately and together, with items mapping onto factors as expected and with small variation in loadings between CCUH and Meyer.

Pearson chi-squared analysis was used to compare participants in Florence and Riga with respect to the type of respondent to the questionnaire and their sociodemographic characteristics; age, citizenship, level of education and employment status.

Fisher's exact analysis was used to compare distribution of scores for each comparable question between Meyer and Riga hospitals, including $p$-values.

Five survey domains were included in the analysis: experience of children and adolescents, caregiver's experience, ward admission and comfort, discharge phase and overall evaluation. The dimensions and number of question items populating each domain are reported in Table 2.

Since the proportion of adolescents in the responder's population who completed the questionnaire autonomously is lower than 3\% in both hospitals and for other respondents it is not possible to state the degree of autonomy of the child in the response process, the analysis was conducted on all data together, so that the responses provided by children and adolescents themselves and their caregivers are reported jointly.

\section{Qualitative analysis: anecdotal evidence}

There are six open-ended questions in the survey used at $\mathrm{CCUH}$ and five open-ended questions in the survey used at Meyer. These sections are presented to respondents as space for 'storytelling'.

Open-ended questions provide richer and more subjective information than closed-ended questions about selected dimensions of the patient journey: ward admission, hospitalization experience of children and adolescents, caregiver's point of view, ward environment and staff evaluation.

In the survey used at CCUH the additional openended question addresses child, adolescent and caregiver experience during their stay in the emergency department.

An interpretative grid was created by extracting three scaled judgments (negative, intermediate, positive) for each of the five areas of storytelling, eliminating the extreme judgments (of which there were few).

\section{Results}

\section{Participants' characteristics}

In Florence, 2834 caregivers who gave consent to participate in the survey were contacted either by e-mail or text message, with 14,568 contacted during the same period in Riga. Response rates are included below. 
Table 2 Domains and dimensions of the questionnaires for Meyer and CCUH patients and caregivers

\begin{tabular}{|c|c|c|}
\hline Domain & Dimension & Number of question items \\
\hline Experience of children and adolescents & $\begin{array}{l}\text { 'patient-provider communication' } \\
\text { 'respect and dignity' } \\
\text { 'fears and anxiety' } \\
\text { 'pain' } \\
\text { 'involvement' }\end{array}$ & 13 \\
\hline Caregiver's experience & $\begin{array}{l}\text { 'caregiver-provider communication' } \\
\text { 'fears and anxiety' } \\
\text { 'privacy' } \\
\text { 'involvement' } \\
\text { 'information' } \\
\text { 'team work' }\end{array}$ & 8 \\
\hline Ward admission and comfort & $\begin{array}{l}\text { 'kindness and courtesy at the admission' } \\
\text { 'cleanliness' } \\
\text { 'silence' } \\
\text { 'food' } \\
\text { 'entertainment' }\end{array}$ & 4 \\
\hline Discharge phase & $\begin{array}{l}\text { 'information' } \\
\text { 'training' }\end{array}$ & 9 \\
\hline Overall evaluation & $\begin{array}{l}\text { 'care' } \\
\text { 'child's health' }\end{array}$ & 2 \\
\hline
\end{tabular}

The large differences in the invited and returned numbers between Meyer and CCUH is assumed to be primarily a consequence of different enrolment approaches, as specified in the methods section, with $\mathrm{CCUH}$ taking an opt-out approach and Meyer an opt-in approach (for more detail, see Table 3).

For Meyer, the majority of respondents are mothers alone (65\%), followed by fathers alone (16\%) and parents alone (9\%). The earlier majority of respondents are aged between 39 and 45 years. Reported citizenship was Italian for (94\%) of females and (96\%) of males. High school diplomas are held by $(38 \%)$ of female and $(45 \%)$ of male respondents, with (47\%) and (29\%) respectively holding a university degree.

In Riga, the majority of respondents are mothers alone $(80 \%)$, followed by mothers together with the adolescents $(7 \%)$ and fathers alone (6\%). The earlier majority of respondents are aged between 32 and 38 years. (97\%) of females and (92\%) of males are Latvians and both female and male respondents mainly have a university degree $(71 \% ; 58 \%)$ and a high school diploma (24\%; $33 \%)$.

We used a Pearson chi-squared analysis to investigate differences among socio-demographic variables between the two groups. For age, type of respondents, citizenship, education and employment status, the differences between Italian and Latvian respondents were small but significant $(P=0.000)$, as expected given the sample size. Socio-demographic details are included in Additional file 1.

\section{Fisher's exact analysis}

In presenting the results below, it is important to consider the analytical approach and participants' characteristics described above: the significant majority of responses are provided by a carer, with only a small minority provided by children or adolescents together with a carer, and direct responses by adolescents representing only a few percentage points (see above and Additional file 1 for details). It is not possible to determine the degree of involvement of the child or adolescent when responding together with a parent. Given the very low numbers of direct responses from children and adolescents, and the broader focus of this study, all results are reported together. As such, unless explicitly stated otherwise, all reporting of experience includes data that are directly reported by children or adolescents as well as that reported in conjunction with a caregiver, and - as in the vast majority of cases - that are proxy reported by a carer.

In general, the mean scores for domains within child and adolescent experience, caregiver experience, and ward admission and comfort are very closely matched between Meyer and $\mathrm{CCUH}$, though within these means there is some divergence; in some cases, scores from Meyer hospital are more skewed towards both the highest and lowest ends of the spectrum, while CCUH is more grouped around the mean. This is the case for

Table 3 Number of discharged patients contacted and responses, per hospital

\begin{tabular}{llllll}
\hline & Invited & Returned & Returned response rate & Returned fully completed & Fully complete response rate \\
\hline Meyer & 2834 & 1661 & $58.61 \%$ & 1080 & $38.11 \%$ \\
CCUH & 14,568 & 6585 & $45.20 \%$ & 4732 & $32.48 \%$ \\
\hline
\end{tabular}


experience of children and adolescents in being treated with respect and dignity by nurses and by other ward staff, and for being involved in decisions about their care as much as they would like; for caregiver experience, this effect is observed for privacy, involvement, information, and team work. In the ward comfort domain, the effect is seen for scores relating to food, and ward entertainment. The result is that the hospitals from both countries provide almost the same mean scores.

The exception is for the discharge phase, where CCUH has higher mean scores than Meyer. The following paragraphs set out these results in full.

\section{Experience of children and adolescents}

As can be seen in the table below, in the 'patient-provider communication' and 'respect and dignity' dimensions, patients at Meyer report a slightly more positive experience than at $\mathrm{CCUH}$.

Questions without significant differences ( $p$-value> 0.05 ) were those related to being encouraged to ask questions by nurses, being treated in a right way according to age, being treated with respect and dignity by doctors $(p<0.100)$, supported in facing fears and anxiety, and helped for pain management. Other questions showed differences with $p$-value $<0.05$ or smaller.

Table 4 shows the percentage of respondents indicating the lowest possible or highest possible experience scores for each question (\% of respondents) in the patient experience domain.

The different distributions between the two is well illustrated by questions asking about being given clear explanations: in Meyer, it emerged that children and adolescents were always given understandable explanations by doctors and nurses 63 and $64 \%$ of the time, and that they were usually understandable $26 \%$ of the time. In Riga, explanations were always clear 55 and $51 \%$ of the time, and usually clear 35 and $37 \%$ of the time.

\section{Caregiver's experience}

As shown in the table below, caregivers at Meyer hospital reported slightly better experience for most items within this domain: having their fears and anxieties addressed, being involved in choices, kept informed, and ward staff working together. Differences in mean scores are very small, with better reported experience in Meyer driven by higher scores on the always responses, alongside lower scores on the usually domain. Since mean differences are very small, full results are reported only in the appendix. Caregivers at CCUH reported better experience for being given privacy to discuss the care of the patient and being given clear answers by doctors, driven by higher scores on both always and usually answers. All show low $p$-values $(\mathrm{p}$-value $=0.000)$. There were no significant differences between the hospitals on the questions of having their fears and anxieties addressed and being given clear answers by nurses ( $p$ value $>0.05$ ).

Table 5 shows the percentage of respondents indicating the best possible or worst possible experience for each question (\% of respondents) in the caregiver experience domain.

In Fig. 1, to illustrate the variability among dimensions within this domain, we represented the means of the answers provided for each question item composing this domain. Response-scales vary across and within sections of the questionnaire so all responses were normalized to a 1-10 scale to make results comparable.

Table 4 Lowest and highest scores by dimension in the patient experience domain (\%)

\begin{tabular}{|c|c|c|c|c|c|c|}
\hline \multirow[b]{2}{*}{ Dimension } & \multirow[b]{2}{*}{ Item } & \multicolumn{2}{|l|}{ CCUH } & \multicolumn{2}{|l|}{ Meyer } & \multirow[b]{2}{*}{ Fisher's exact } \\
\hline & & Lowest & Highest & Lowest & Highest & \\
\hline Patient-provider communication & Listened carefully by doctors & 0.50 & 61.92 & 1.46 & 62.93 & 0.001 \\
\hline Patient-provider communication & Listened carefully by nurses & 0.45 & 59.64 & 0.00 & 66.59 & 0.017 \\
\hline Patient-provider communication & Given clear explanations by doctors & 1.39 & 54.73 & 2.20 & 63.17 & 0.002 \\
\hline Patient-provider communication & Given clear explanations by nurses & 2.03 & 50.62 & 1.71 & 63.90 & 0.000 \\
\hline Patient-provider communication & Encouraged to ask by doctors & 8.33 & 33.76 & 11.95 & 36.34 & 0.045 \\
\hline Patient-provider communication & Encouraged to ask by nurses & 9.97 & 29.45 & 11.22 & 32.93 & 0.340 \\
\hline Patient-provider communication & Treated in an age proper way & 0.73 & 59.36 & 0.93 & 60.71 & 0.114 \\
\hline Respect and dignity & Respect and dignity by doctors & 0.32 & 81.56 & 0.00 & 85.46 & 0.073 \\
\hline Respect and dignity & Respect and dignity by nurses & 0.14 & 73.76 & 0.18 & 82.31 & 0.000 \\
\hline Respect and dignity & Respect and dignity by other ward staff & 0.61 & 65.54 & 0.71 & 79.64 & 0.000 \\
\hline Fears and anxiety & Fears and anxiety & 1.59 & 55.46 & 1.84 & 57.58 & 0.619 \\
\hline Pain & Pain & 0.64 & 73.97 & 0.41 & 75.16 & 0.762 \\
\hline Involvement & Involvement & 6.08 & 43.92 & 4.24 & 58.47 & 0.044 \\
\hline
\end{tabular}




\section{Ward admission and comfort}

Regarding the dimension of 'kindness and courtesy at the admission', illustrated in Fig. 2, respondents from Meyer scored higher than respondents from $\mathrm{CCUH}$, with $p$-value $=0.000$.

In Fig. 2, the scores correspond to the 5-level response scale of the question regarding being treated with kindness and courtesy at the time of admission, ranging from the lowest score $(1=$ red $)$ corresponding to "Not at all" to the highest score $(5=$ dark green) corresponding to "Very much".

Additionally, respondents from CCUH reported better scores for lack of noise and cleanliness, while those from Meyer scored more highly on satisfying food, and appropriate entertainment. All $p$-values are low ( $\mathrm{p}$-value $=$ $0.000)$.

Table 6 shows the percentage of respondents indicating the best possible or worst possible experience for each question (\% of respondents) in the ward comfort domain.

Again, in Fig. 3, in order to show variability among dimensions within this domain, we represented the means of the answers provided for each question item composing this domain, after adjusting them from different response scales to a 1-10 scale.

\section{Discharge phase}

The discharge phase showed the greatest divergence of mean scores, and overall higher scores for CCUH, unlike for the domains described above.

Compared with Meyer, respondents at CCUH report a slightly more positive experience with respect to a number of dimensions in this domain, namely:

- if a provider asked the caregiver if she had concerns about whether the child or adolescent was ready to leave $(49 \% ; 73 \%)$ with $p$-value $=0.000$

- if a provider talked with the caregiver as much as she wanted about how to care for the child's or adolescent's health after leaving the hospital (79\%; $86 \%)$ with p-value $=0.000$
- if a provider explained in a way that was easy to understand when the child or adolescent could return to his or her daily activities (73\%; 74\%) with $p$-value $<0.01$

- if a provider explained in a way that was easy to understand how the child or adolescent should take new medicines after leaving the hospital (87\%; 92\%) with $p$-value $<0.05$

- if a provider explained in a way that was easy to understand what symptoms or health problems to look out for after leaving the hospital (73\%; 74\%) although differences are not statistically significant

- if the information written in the discharge letter was clear $(44 \% ; 46 \%)$ with $p$-value $<0.01$

- if the information written in the received materials (except the discharge letter) was clear (43\%; 48\%) with $\mathrm{p}$-value $=0.000$

On the other hand, respondents at Meyer report a slightly more positive experience than at $\mathrm{CCUH}$ in this domain regarding:

- if a provider explained in a way that was easy to understand about possible side effects of the new medicines $(49 \%$; $41 \%)$ with p-value $<0.01$

- if the specific training received in order to personally take care of the child or adolescent once back home was useful $(61 \% ; 52 \%)$ with $p$-value $=0.000$

Table 7 shows the percentage of respondents indicating the best possible or worst possible experience for each question (\% of respondents) in the discharge phase domain.

\section{Overall evaluation}

The majority of respondents, either at Meyer or at $\mathrm{CCUH}$, reported that the care received by the child or adolescent in the ward was very good (63\%; 59\%), while a significant percentage of these two groups reported that it was good $(31 \%$; 33\%). Respondents at Meyer,

Table 5 Lowest and highest scores by dimension in the caregiver experience domain (\%)

\begin{tabular}{|c|c|c|c|c|c|c|}
\hline \multirow[b]{2}{*}{ Dimension } & \multirow[b]{2}{*}{ Item } & \multicolumn{2}{|l|}{$\mathrm{CCUH}$} & \multicolumn{2}{|l|}{ Meyer } & \multirow[b]{2}{*}{ Fisher's exac } \\
\hline & & Lowest & Highest & Lowest & Highest & \\
\hline Fears and anxiety & Fears and anxiety & 2.36 & 54.36 & 2.24 & 56.91 & 0.422 \\
\hline Privacy & Privacy & 1.62 & 57.84 & 6.17 & 51.37 & 0.000 \\
\hline Involvement & Involvement & 3.57 & 52.27 & 2.06 & 61.06 & 0.000 \\
\hline Caregiver-provider communication & Doctor-caregiver communication & 0.37 & 76.56 & 0.35 & 75.13 & 0.000 \\
\hline Caregiver-provider communication & Nurse-caregiver communication & 0.39 & 69.95 & 0.62 & 68.08 & 0.365 \\
\hline Information & Information & 1.67 & 47.96 & 1.63 & 65.95 & 0.000 \\
\hline Team work & Team work & 0.45 & 51.50 & 1.47 & 55.54 & 0.000 \\
\hline
\end{tabular}




\section{Caregiver's experience}

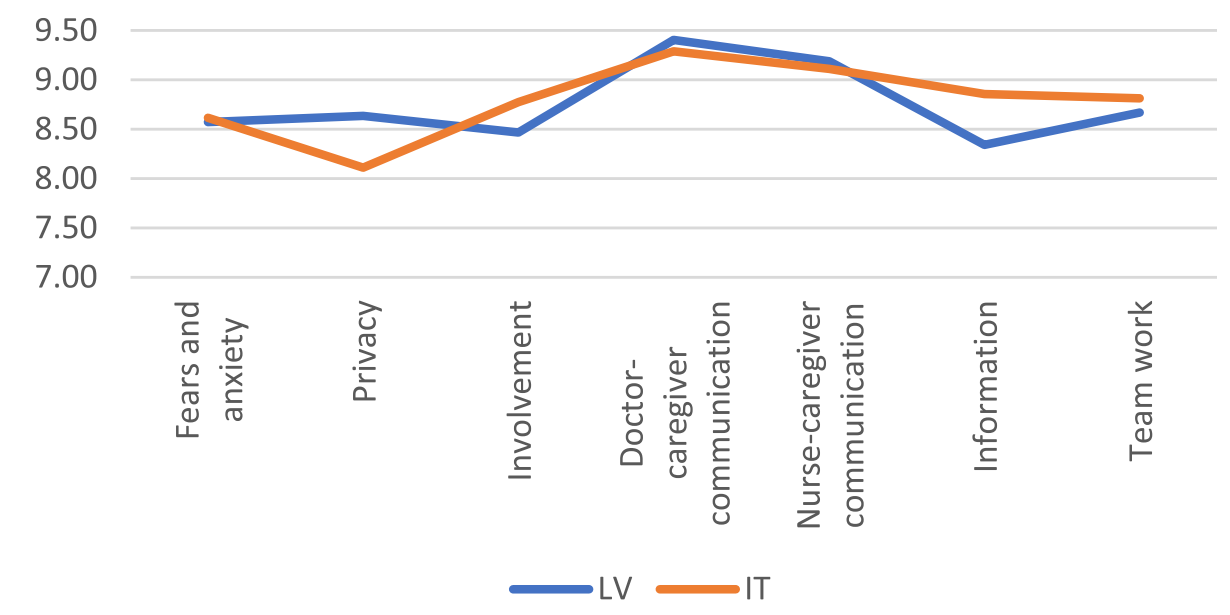

Fig. 1 Mean caregiver experience scores

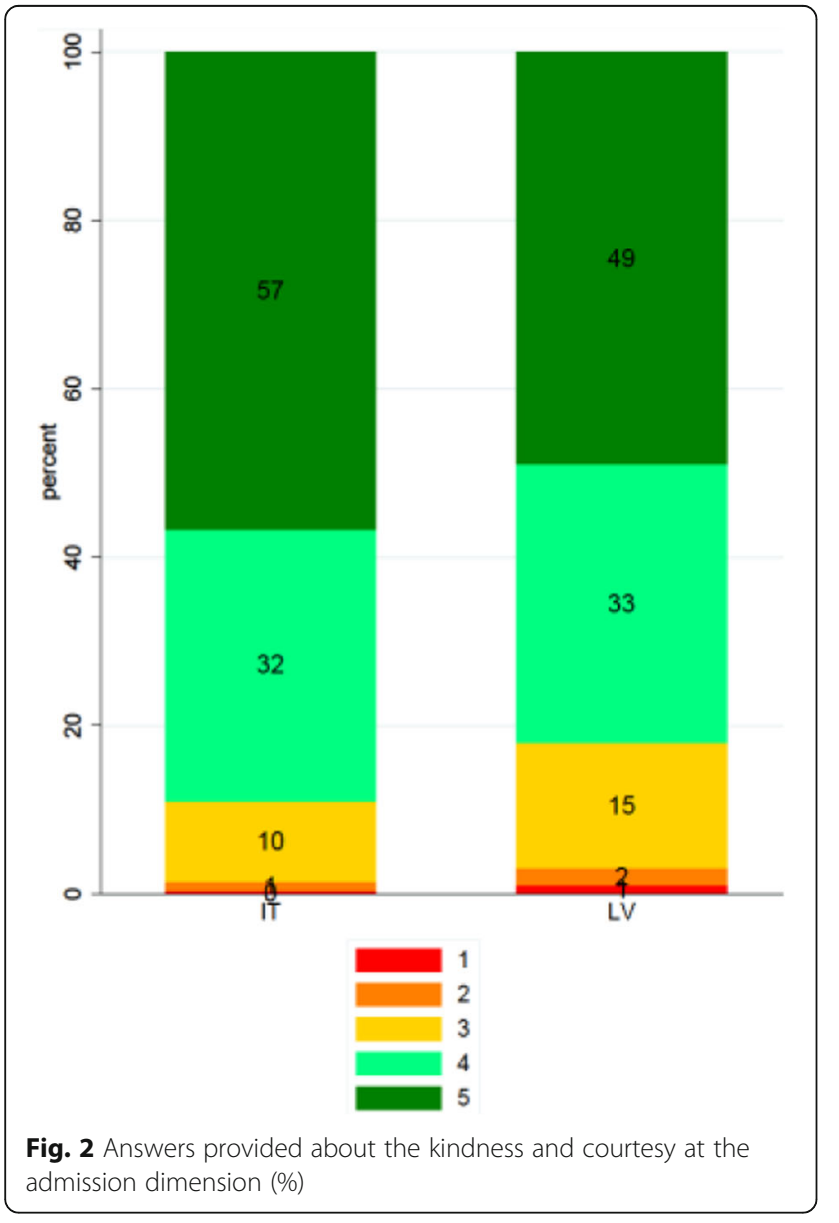

again, report a slightly more positive experience than at CCUH with p-value $=0.000$.

Finally, the majority of respondents, either at Meyer or at CCUH, reported the child's or adolescent's current health status as good $(34 \% ; 30 \%)$, with a significant percentage of these two groups reporting that it is very good (19\%; 13\%). The latter cannot be considered as an indicator of quality of care as it is not possible to control for initial health status or case-mix of respondents.

Full results of Fisher's exact analysis, with significance values, are included in Additional file 1.

\section{Anecdotal evidence from open comments}

Analysis of comments received at Meyer shows a high proportion of children and adolescents or carers choose to provide narrative comments, with a majority of positive comments. Questions addressed directly to children and adolescents were often answered by them in the first person, although it is not possible to verify to what extent these responses are autonomously provided by children and adolescents, or mediated by carers. Other items are expected to have been completed by the caregiver. Analysis of comments using text analysis software identified the most frequently used terms in storytelling as kindness, availability and professionalism.

Most narrative comments at CCUH are provided by parents to thank staff for caring for their children. Of more than 7000 comments - 30\% were negative or contained some suggestions for improvement. Most recommendations were about improving the environment and food quality. Most of positive comments were about kind and positive attitudes and clear communication.

From the ward admission stage, typical comments show that it is important to provide children, adolescents and 
Table 6 Lowest and highest scores by dimension in the ward comfort domain (\%)

\begin{tabular}{|c|c|c|c|c|c|}
\hline \multirow[b]{2}{*}{ Dimension } & \multicolumn{2}{|l|}{$\mathrm{CCUH}$} & \multicolumn{2}{|l|}{ Meyer } & \multirow[b]{2}{*}{ Fisher's exact } \\
\hline & Lowest & Highest & Lowest & Highest & \\
\hline Silence & 1.56 & 54.95 & 1.09 & 33.19 & 0.000 \\
\hline Cleanliness & 0.47 & 55.73 & 0.50 & 28.34 & 0.000 \\
\hline Food catering service & 5.46 & 28.10 & 3.73 & 44.08 & 0.000 \\
\hline Entertainment & 24.75 & 53.43 & 14.80 & 64.72 & 0.000 \\
\hline
\end{tabular}

their caregivers with information on what they should expect from the hospital stay, for example which test and examinations will be performed and their expected waiting times. Another relevant fairly common concern regards room assignment and availability of beds, in particular for scheduled admissions. On the other hand, other comments note that admission is often quick and comfortable, and ward personnel are kind and warmly welcoming.

In the hospitalization experience of children and adolescents, some points relate to difficulties in the interpersonal relationships between the child or adolescent and the hospital staff. Although ward staff were usually reported as polite, there are sometimes difficulties expressed in communication with health workers. However, generally a very positive attitude emerges from the child, with hospital staff perceived as paying lots of attention to children and adolescents, making their overall experience of hospitalization positive.

Common criticisms from the adult's perspective relate to interpersonal relationships towards children, adolescents and their caregivers, notably insensitivity, challenges in getting desired information, and the impression of a lack of information exchange between hospital staff. This last observation can be usefully compared with the questionnaire question "How would you rate the ability of the ward medical and nursing staff to work together?", for which responses are largely positive (very good $55.10 \%$ and good $34.33 \%$ ). However, for the share of caregivers who found it deficient, this aspect was evidently relevant to them, as highlighted by several comments in the storytelling (example shown in Additional file 1).

A significant number of respondents were critical about the ward environment, especially regarding the quality and efficiency of food catering service during the hospitalization. Nevertheless, generally, there is a positive opinion of many wards where children and adolescents are hospitalised, especially in terms of cleanliness, equipment and comfort.

Finally, when evaluating the hospital staff, comments are generally very positive, with respondents expressing gratitude to those who took care of them.

The themes emerging are as expected based on what patients are known to value during their hospitalisation experience. Additionally, these insights show that open comments can be a tool to value and motivate personnel; responses clearly illustrate that each health worker can make a difference in the child's and adolescent's experience, and that the respondents are able to recognize their important role in service provision.

\section{Ward comfort}

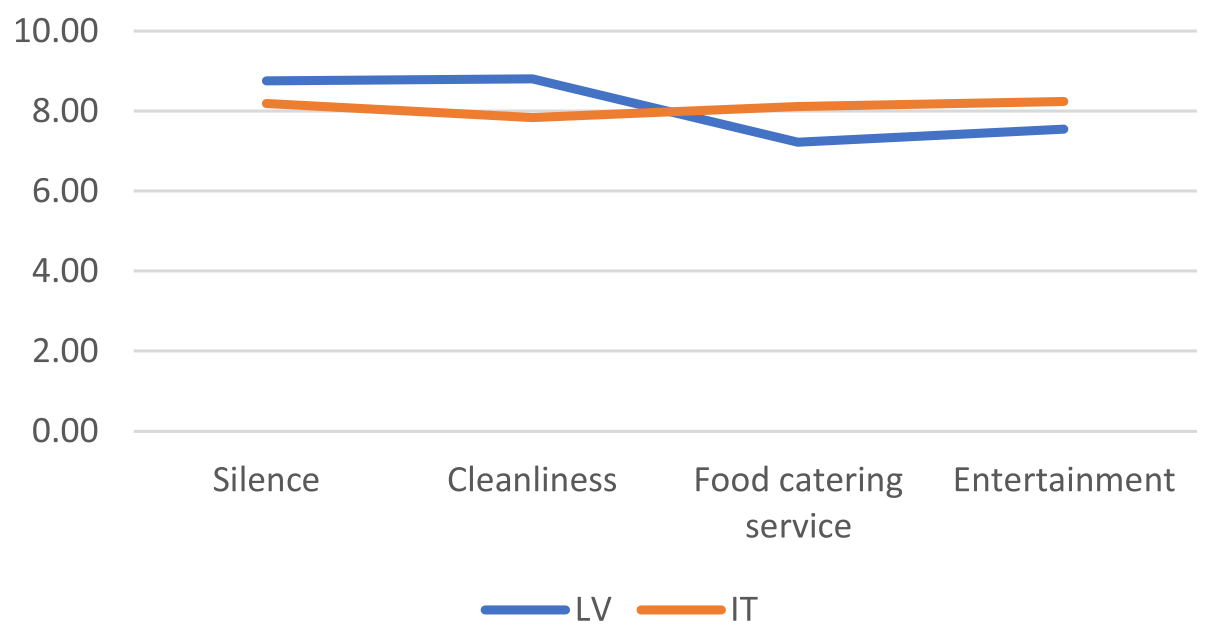

Fig. 3 Mean ward comfort scores 
Table 7 Lowest and highest scores by dimension in the discharge phase domain (\%)

\begin{tabular}{|c|c|c|c|c|c|c|}
\hline \multirow[b]{2}{*}{ Dimension } & \multirow[b]{2}{*}{ Item } & \multicolumn{2}{|l|}{ CCUH } & \multicolumn{2}{|l|}{ Meyer } & \multirow[b]{2}{*}{ Fisher's exact } \\
\hline & & Lowest & Highest & Lowest & Highest & \\
\hline Information & Ready to be discharged & 10.97 & 72.88 & 30.60 & 49.08 & 0.000 \\
\hline Information & Managing care at home & 3.31 & 85.99 & 4.93 & 78.51 & 0.000 \\
\hline Information & Back to daily routine & 10.44 & 74.36 & 8.11 & 73.16 & 0.002 \\
\hline Information & New drugs administration & 1.46 & 91.75 & 2.93 & 88.64 & 0.016 \\
\hline Information & New drugs side effects & 41.03 & 40.50 & 36.14 & 49.05 & 0.001 \\
\hline Information & Symptoms to monitor & 9.51 & 74.22 & 11.27 & 73.28 & 0.244 \\
\hline Information & Discharge letter & 0.46 & 45.65 & 0.66 & 43.64 & 0.001 \\
\hline Information & Other written materials & 0.18 & 48.37 & 0.19 & 42.78 & 0.000 \\
\hline Training & Training & 0.35 & 51.77 & 0.24 & 60.99 & 0.000 \\
\hline
\end{tabular}

Comments can also be used to identify potential improvements; it clearly emerges that ward staff could sometimes better understand the impact their behaviours have on children and adolescents, for example in choosing the right time and place to have breaks and personal interactions, or in giving the appearance of detachment from children, adolescents and carers. The different absolute numbers of comments for Meyer and CCUH correspond to the difference in the numbers of returned questionnaires (see Table 8). A sample of the comments is presented in Additional file 1, selected to represent the range of expressed views.

\section{Discussion}

The model of continuous digital collection of paediatric PREMs described above appears to be a feasible option for collecting paediatric PREMs at scale (see also [18]). The large population reached in both countries indicates that the interface between survey platform and hospital data systems is an effective method of survey administration, while high response rates suggest that the electronic collection model is acceptable and convenient for respondents. The difference between survey responses and fully completed survey responses of around a third in both hospitals suggests that the current questionnaire may be overly long, discouraging full completion among some respondents - although this should be considered with reference to the different enrolment methods.

The collection of qualitative comments is important in sustaining front line staff interest, and increases the insight possible from data collection by providing greater richness of information - though how far this applies depends on the developmental status of respondents and may not always hold true for younger children. In future, approaches such as text mining and natural language processing could facilitate the use of qualitative comments in identifying improvement opportunities and potentially to derive new insights to improve the experience of children and adolescents through analysis of large numbers of qualitative responses. The data platform and hosting provide a simple way for hospital teams to access data at different levels of granularity, as well as enabling secondary analysis and application of advanced analytical techniques.

Insights gathered from hospital staff in management of the model report a differentiated use of answers according to their nature. Hospital management use negative answers to identify problems in care delivery and intervene promptly in order to resolve them. Positive answers are used to motivate all categories of hospital staff, diffuse positive behaviours within the organization and spread good practices through a Learning from Excellence (LfE) model [19].

The data indicate that both hospitals provide good experience for children and adolescents - as reported by caregivers - with little variation in performance across experience domains. There is a notable extent of agreement between respondents in the two countries, despite attending hospitals with different cultures and systems, having different cultural backgrounds, different levels of wealth in the European context, and different languages. Further exploration of the role of cultural differences in reported patient experience would enable a more nuanced interpretation of the distributions of scores.

Table 8 Number of free text comments received

\begin{tabular}{lllllll}
\hline $\begin{array}{l}\text { Emergency } \\
\text { department }\end{array}$ & $\begin{array}{l}\text { Ward } \\
\text { admission }\end{array}$ & $\begin{array}{l}\text { Hospitalization experience of children } \\
\text { and adolescents }\end{array}$ & $\begin{array}{l}\text { Caregiver's point } \\
\text { of view }\end{array}$ & $\begin{array}{l}\text { Ward } \\
\text { environment }\end{array}$ & $\begin{array}{l}\text { Staff } \\
\text { evaluation }\end{array}$ & $\begin{array}{l}\text { Total } \\
\text { Meyer n n/a }\end{array}$ \\
CCUH 1294 & 733 & 290 & 486 & 432 & 552 & 2493 \\
\hline
\end{tabular}


However, these differences must be set in the context of some similarities: Latvia and Italy are both European countries and members of the European Union, both participating organisations are specialist paediatric hospitals and based in cities, and both are regarded as high performing and are members of the European Children's Hospitals Organisation (CCUH joined ECHO during the period of this study).

The qualitative comments suggest that the similar results are because there are broadly shared preferences among children and adolescents in the two countries, and that both hospitals in this study are similarly effective at meeting expectations - or at least, as reported by carers.

The major limitation of the model is that the questionnaire is not entirely framed for and offered exclusively to children and adolescents, given that the purpose is to measure their experiences of hospitalization. While this is the approach for most surveys of children and adolescents, and parental reporting is a good source of information for younger children especially [20], there is evidence that surveys can be developed which are feasible and acceptable for children over the age of 8 to answer directly, and that their responses provide additional insights to those available from parental responses alone [21].

The survey described here was based on an existing adult experience survey, adapted such that it can be filled in by parents or adolescents. On the one hand, this can enable comparison of items between paediatric and non-paediatric hospitals, supporting evaluation and learning, and enables a single survey to be used rather than multiple surveys for different age groups [22]; on the other, the survey may lack relevant items for youthfriendly healthcare [23], may not be best configured to encourage clarity and minimise fatigue among respondents, and is not appropriate for younger children to fill in directly.

This feature may have encouraged the situation that, although adolescents were invited to participate in the survey autonomously, parents responding alone form the significant majority of total respondents. More specifically, parents responding with a child or adolescent represent a significant minority, while adolescents alone form only a minimal proportion of respondents (3\%). A survey which could be filled in autonomously by a wider selection of children and adolescents would require significant development work (or validation of a preexisting survey for these settings), but could capture additional insights into the experiences of children and adolescents in participating hospitals. Further research in CCUH and Meyer hospitals would be of value to determine how the survey could be developed to make it appropriate for younger children to autonomously complete. Additionally, there could be value in developing separate developmentally-appropriate versions of the questionnaire for children, adolescents and carers, rather than embedding all questions in a questionnaire mostly answered by caregivers. Such an adjustment process would apply to both the closed-ended and open-ended questions.

Another limitation is that we do not know the demographic details of all those who were invited to participate in the survey, and therefore cannot determine how proportionate the number of responding adolescents is to all those invited, and to the total eligible patient population. This issue further complicates the analysis of results and makes more unclear how far this "proxy reporting by parents" effect is driven by the survey enrolment or administration model, by the survey itself, or by something else. Including a function in the PREMs administration system to collect the demographic characteristics of all those who were invited to participate in the survey could help address this.

Finally, the impossibility of case mix comparisons or of adjusting for initial health status may be considered a limitation in our analysis, although evidence on the link between patient experience and severity of disease is inconclusive.

There was no formal pilot period in developing the PREMs model, which helps explain a number of the limitations described here. This was due to the need to align with timelines determined by the wider Latvian HSPA development, supported by the structural reform programme, which necessitated a shorter period of development and testing than could include e.g. development and testing of bespoke surveys for different developmental levels. The priority for the initial phase of operation was to implement the technologies and processes which enable the collection of survey data at scale. Operating the PREMs survey within the two hospitals has served as the proof-of-concept and establishment of protocols; subsequent in-country ownership and leadership of PREMs collection could provide the opportunity to resolve the most important of the limitations described above. As well as potential adjustments to the recruitment process or to the survey itself, this might additionally include greater ability to categorise responses by disease group and to provide an additional level of insight than the currently available ward level. The benefits available from benchmarking suggest any changes should be implemented in both Meyer and CCUH hospitals to ensure ongoing comparability.

\section{Conclusions}

In this study we demonstrate the possibility of establishing an international benchmarking system for paediatric PREMs in two European countries, and compare survey responses between Florence and Riga. 
The features of this PREMs collection and management model are relevant for researchers and policymakers as well as for front line staff and managers. The OECD [9] criteria to determine the scope of conditions and sectors for patient reported data collection are: actionability, relevance, cost of implementation, availability of measures and feasibility of collection. The model implemented in Meyer and CCUH is well suited to all these criteria: a high response rate, cheap and efficient contact to and data collection from a wide population, and simple, efficient recording and collating of responses in real time. While there are limitations which could be addressed - notably the current reliance on proxy carer reporting of child and adolescent experience - the model enables a large, longitudinal dataset to be collected over time, providing greater use as a management tool and for the purposes of benchmarking. This model could be effective at meeting the OECD's criteria, help deliver the call for expansion of PREM data collection, and enable a focus on international benchmarking.

The insights and value possible from benchmarking in this way would increase as the number of comparators increases; other countries or providers seeking to commence or derive greater benefit from PREM data collection may wish to explore adopting this or comparable models of data collection. The continuous data collection and large eligible population (as opposed to periodic sampling methods) make this model particularly useful for benchmarking, notably through allowing real time or retrospective investigation of discrete events and evaluations of initiatives by bringing in scope additional analytical techniques, such as interrupted time series analysis.

Accordingly, further research of practical benefit should include the wider benchmarking of CCUH and Meyer with other specialist paediatric hospitals and other paediatric respondents in a general hospital, and exploring the drivers of variation in these scores. From this, new insights may emerge regarding the most effective ways to deliver a positive experience for children and adolescents, as well as approaches which help deliver important domains of patient experience - whether associated with overall satisfaction or not. It is our hope that such research will become increasingly possible and widespread as other countries and providers heed the call of the OECD and adopt PREMs models which enable international benchmarking, particularly those providing large longitudinal data sets as described here.

In the longer term, a valuable focus would be to extend this or similar digital, continuous systems for paediatric PREMs collection and analysis to other national and international hospitals. In doing so, a larger network of healthcare organizations sharing a common benchmarking platform could be established to support continuous performance improvement.
Moreover, future research should also investigate how the PREMs system was implemented in each healthcare system, and to understand how this affects participation rates and staff support for the programme. Additional research of value would evaluate the use of the data return web platform as a management tool to improve the quality of care.

\section{Supplementary Information}

The online version contains supplementary material available at https://doi. org/10.1186/s12913-021-06094-z.

\section{Additional file 1.}

Additional file 2.

\section{Abbreviations}

PREMs: Patient Reported Experience Measures; Meyer: Meyer Children's University Hospital; CCUH: Children's Clinical University Hospital; CYP: Children and Young People; OECD: Organisation for Economic Cooperation and Development; HSPA: Health System Performance Assessment; SRSS: Structural Reform Support Service; API: Application Programming Interface; CAHPS: Consumer Assessment of Healthcare Providers and Systems; MeS Lab: Management and Healthcare Laboratory; LfE: Learning from Excellence; ECHO: European Children's Hospitals Organisation

\section{Acknowledgments}

We wish to thank Professor Sabina Nuti, Dr. Manila Bonciani and Dr. Sabina De Rosis for their precious suggestions for the paper and their direction of the described activities.

\section{Authors' contributions}

IC, in collaboration with other authors, led and supervised the PREMs implementation at Meyer and CCUH. IC and KJG conducted the statistical analyses and wrote the manuscript. FM and VA extracted and selected freetext comments. All authors were involved in interpreting the findings, and reviewing and approving the manuscript.

\section{Authors' information}

IC is a Ph.D. Candidate at the Institute of Management, Department EMbeDS, Sant'Anna School of Advanced Studies in Pisa, in the Management and Healthcare Laboratory (MeS Lab).

KJG is a Marie Curie research fellow and Ph.D. candidate at the Institute of Management, Department EMbeDS, Sant'Anna School of Advanced Studies in Pisa, in the Management and Healthcare Laboratory (MeS Lab).

VA is the General Director of the Children's Clinical University Hospital of Riga, Latvia.

FM is a medical director within the staff of the Health Director of Meyer in Florence, Italy.

\section{Funding}

The PREMs Surveys at Meyer and CCUH were respectively financed by the Tuscany Region and the European Commission Structural Reform Support Service (SRSS). Both were coordinated by the Management and Healthcare Laboratory (MeS Lab) of Sant'Anna School of Advanced Studies in Pisa (Italy), under the scientific responsibility of Prof. Sabina Nuti. The PREMs Survey at CCUH originated as a pilot project within a wider project financed by the European Commission on behalf of the SRSS (Grant agreement: SRSS/S2017/ 019). The funding bodies collaborated in supervising the design of the surveys and the administration methodology elaborated by the research team, and the return of the preliminary results of the surveys. Moreover, the manuscript was developed with support from a member of a Marie Skłodowska-Curie Innovative Training Network (HealthPros-Healthcare Performance Intelligence Professionals) that has received funding from the European Union's Horizon 2020 research and innovation programme under Grant agreement No. 765141. 


\section{Availability of data and materials}

The datasets analysed are available from the corresponding author upon reasonable request.

\section{Ethics approval and consent to participate}

Formal ethics approvals and informed consent were not needed for the patient surveys, following the advice of the Data Protection Officers of the two hospitals involved. At enrollment, patients were accurately verbally informed and were free to participate or not in the survey. This was established at Meyer in compliance with the national guidelines of the Italian Data Protection Authority (Guidelines on Processing Personal Data to Perform Customer Satisfaction Surveys in the Health Care Sector, http:// www.garanteprivacy.it/web/guest/home/docweb/-/docweb-display/ docweb/3853781), and confirmed as aligned with Latvian requirements by the legal office at $\mathrm{CCUH}$. For the two hospitals, the privacy policy on the processing of personal data was established in accordance with European Regulation 2016/679.

\section{Consent for publication}

Not applicable.

\section{Competing interests}

IC and KJG are employed as researchers by the MeS Lab. FM is a Medical Director at Meyer Hospital. VA is General Director of CCUH.

\section{Author details}

${ }^{1}$ Management and Healthcare Laboratory (MeS Lab), Institute of Management and EMbeDS, Sant'Anna School of Advanced Studies, Piazza Martiri della Libertà 33, 56127 Pisa, Italy. ${ }^{2}$ Azienda Ospedaliero Universitaria Meyer, Viale Pieraccini 24, 50139 Florence, Italy. ${ }^{3}$ Children's Clinical University Hospital, Vienības gatve 45, Rīga LV-1004, Latvia.

Received: 15 May 2020 Accepted: 17 January 2021

Published online: 27 January 2021

\section{References}

1. Gleeson H, Calderon A, Swami V, Deighton J, Wolpert M, Edbrooke-Childs J. Systematic review of approaches to using patient experience data for quality improvement in healthcare settings. BMJ Open. 2016;6(8):e011907 Available from: http://bmjopen.bmj.com/. [cited 2018 Nov 9].

2. Anhang Price R, Elliott MN, Zaslavsky AM, Hays RD, Lehrman WG, Rybowski $L$, et al. Examining the role of patient experience surveys in measuring health care quality. Med Care Res Rev. 2014;71(5):522-54 Available from: http://www.ncbi.nlm.nih.gov/pubmed/25027409. [cited 2019 Jun 20].

3. Doyle C, Lennox L, Bell D. A systematic review of evidence on the links between patient experience and clinical safety and effectiveness. BMJ Open. 2013;3(1):e001570

4. Bodenheimer T, Sinsky C. From triple to quadruple aim: care of the patient requires care of the provider. Ann Fam Med. 2014;12(6):573-6.

5. Jamieson K, De Rosis GS, Claudio Passino FP. Value in healthcare and the role of the patient voice. Healthc Pap. 2019;18(4):28-35 Available from: https://www.longwoods.com/product/26031.

6. Nuti S, De Rosis S, Bonciani M, Murante A. Rethinking Healthcare Performance Evaluation Systems towards the People-Centredness Approach: Their Pathways, their Experience, their Evaluation. Healthc Pap. 2017;17, 56(2):-64 Available from: http://www.longwoods.com/content/25408. [cited 2019 May 9].

7. Nuti S, Noto G, Vola F, Vainieri M. Let's play the patients music. Manag Decis. 2018;56(10):2252-72 Available from: https://www.emeraldinsight.com/ doi/10.1108/MD-09-2017-0907. [cited 2019 May 9].

8. Coulter A, Locock L, Ziebland S, Calabrese J. Collecting data on patient experience is not enough: they must be used to improve care. BMJ. 2014; 348:g2225 Available from: http://www.ncbi.nlm.nih.gov/pubmed/24671966. [cited 2019 May 9].

9. Berwick B, Black N, Cullen D, Deerberg-Wittram J, Degos L, Diverty B, et al. Strengthening the international comparison of health system performance through patient-reported indicators. Recomm TO OECD Minist Heal FROM HIGH Lev Reflect Gr Futur Heal Stat [Internet]. 2017 [cited 2019 May 9]; (January). Available from: https://www.oecd.org/health/health-systems/ Recommendations-from-high-level-reflection-group-on-the-future-of-healthstatistics.pdf.
10. O'Neill J, Reeks GR, Kearney L. Can an interactive application be used to collect meaningful feedback from paediatric patients and their parents in a hospital setting? Patient Exp J. 2018;5(2):69-75.

11. Karisalmi N, Stenhammar H, Kaipio J. What constitutes the patient experience of children? Findings from the photo elicitation and the video diary study. Patient Exp J. 2018;5(2):54-68 Available from: https://pxjournal. org/journal/vol5/iss2/9. [cited 2020 May 8].

12. Söderbäck M, Coyne I, Harder $M$. The importance of including both a child perspective and the child's perspective within health care settings to provide truly child-centred care. J Child Heal Care. 2011;15(2):99-106 Available from: http://journals.sagepub.com/doi/10.1177/1367493510397624 [cited 2020 May 8].

13. Alderson P, Sutcliffe $K$, Curtis K. Children as partners with adults in their medical care. Arch Dis Child. 2006;91(4):300-3.

14. Coyne I. Children's experiences of hospitalization. J Child Heal Care. 2006; 10(4):326-36 Available from: http://journals.sagepub.com/doi/10.1177/13674 93506067884. [cited 2020 May 8].

15. Bevan G, Evans A, Nuti S. Reputations count: why benchmarking performance is improving health care across the world. Heal Econ Policy Law. 2019;14(2): 141-61 Available from: https:/www.cambridge.org/core/product/identifier/S1 744133117000561/type/journal_article. [cited 2019 May 9].

16. Noto G, Corazza I, Klavina K, Lepiksone J, Nuti S. Health system performance assessment in small countries: The case study of Latvia. Int J Health Plann Manage. 2019;34(4):1408-22 Available from: https://onlinelibrary.wiley.com/ doi/abs/10.1002/hpm.2803. [cited 2020 May 8].

17. Agency for Healthcare Research \& Quality. CAHPS Child Hospital Survey Measures [Internet]. 2017 [cited 2020 May 8]. Available from: https://www. ahrq.gov/cahps/surveys-guidance/hospital/about/child_hp_survey.html.

18. De Rosis S, Cerasuolo D, Nuti S. Using patient-reported measures to drive change in healthcare: the experience of the digital, continuous and systematic PREMs observatory in Italy. BMC Health Serv Res. 2020;20(1):315 Available from: https://bmchealthservres.biomedcentral.com/articles/10.11 86/s12913-020-05099-4. [cited 2020 May 8].

19. Kelly $\mathrm{N}$, Blake S, Plunkett $\mathrm{A}$. Learning from excellence in healthcare: a new approach to incident reporting. Arch Dis Child. 2016;101(9):788-91.

20. D'Souza-Vazirani D, Minkovitz CS, Strobino DM. Validity of Maternal Report of Acute Health Care Use for Children Younger Than 3 Years. Arch Pediatr Adolesc Med. 2005;159(2):167-72. https://doi.org/10.1001/archpedi.159.2.167.

21. Hargreaves DS, Sizmur S, Pitchforth J, Tallett A, Toomey SL, Hopwood B, et al. Children and young people's versus parents' responses in an English national inpatient survey. Arch Dis Child. 2018;103(5):486-91 Available from: http://adc.bmj.com/content/103/5/486.abstract.

22. Varni JW, Limbers CA, Burwinkle TM. Parent proxy-report of their children's health-related quality of life: an analysis of 13,878 parents' reliability and validity across age subgroups using the PedsQ $L^{\mathrm{TM}} 4.0$ generic Core scales. Health Qual Life Outcomes. 2007;5(1):2. https://doi.org/10.1186/1477-7525-5-2.

23. Ambresin A-E, Bennett K, Patton GC, Sanci LA, Sawyer SM. Assessment of youth-friendly health care: a systematic review of indicators drawn from young people's perspectives. J Adolesc Heal Off Publ Soc Adolesc Med. 2013;52(6):670-81.

\section{Publisher's Note}

Springer Nature remains neutral with regard to jurisdictional claims in published maps and institutional affiliations.

Ready to submit your research? Choose BMC and benefit from:

- fast, convenient online submission

- thorough peer review by experienced researchers in your field

- rapid publication on acceptance

- support for research data, including large and complex data types

- gold Open Access which fosters wider collaboration and increased citations

- maximum visibility for your research: over $100 \mathrm{M}$ website views per year

At BMC, research is always in progress.

Learn more biomedcentral.com/submissions 